\title{
O futuro da educação em uma sociedade do conhecimento: \\ o argumento radical em defesa de um currículo centrado em disciplinas*
}

\author{
MICHAEL F. D. YOUNG \\ Universidade de Londres \\ Tradução de Laura Beatriz Áreas Coimbra \\ Revisão Técnica de Antonio Flavio Barbosa Moreira
}

\section{INTRODUÇÃO}

Escreve-se muito, em políticas educacionais atuais, sobre a preparação de estudantes para uma sociedade do conhecimento e o papel importante a ser desempenhado pela educação. Essas políticas, entretanto, dizem muito pouco sobre o papel do conhecimento em si, na educação (Young, 2009a). Em outras palavras, o que é importante que os nossos jovens saibam? Ainda mais preocupante que isso, muitas políticas atuais quase sistematicamente ignoram ou marginalizam a questão do conhecimento. A ênfase, invariavelmente, recai nos aprendizes, seus estilos diferentes de aprendizagem e seus interesses, nos resultados mensuráveis de aprendizagem e competências e, ainda, em como tornar o currículo relevante para suas experiências e sua futura empregabilidade. $\mathrm{O}$ conhecimento, de alguma forma, é visto como inquestionável, ou como algo que podemos adequar às nossas metas políticas (Young, 2010).

Não seria exagero, no caso da Inglaterra, da Escócia e de alguns outros países europeus, dizer que as recentes reformas de currículo estão levando a uma redução ou mesmo a um “esvaziamento do conteúdo”, especialmente para aqueles que já não

* Artigo originalmente publicado no Journal of the Pacific Circle Consortium for Education (it), v. 22, n. 1, dez. 2010, pp. 21-32. Autorizada a tradução e publicação pelo autor. 
estão tendo sucesso na escola (Yates;Young, 2010). Frequentemente, essas reformas são bem intencionadas e têm objetivos progressistas. Enfatizam abertura de acesso, maior participação e promoção de inclusão social. Isso torna difícil questioná-las sem parecer conservador e elitista.

Neste artigo, quero argumentar que, se vamos dar um sentido sério à importância da educação em uma sociedade do conhecimento, é necessário tornar a questão do conhecimento nossa preocupação central, e isso envolve o desenvolvimento de uma abordagem ao currículo baseada no conhecimento e na disciplina, e não baseada no aprendiz, como presume a ortodoxia atual. Além disso, eu argumentaria que essa é a opção "radical" - não, como afirmam alguns, a opção conservadora desde que saibamos claramente o que significa, para nós, conhecimento. Uso a palavra "radical" aqui para me referir à questão chave que a maioria dos países enfrenta hoje: a persistência de desigualdades sociais na educação. Prefiro a palavra "radical" a alternativas como "progressista" e "crítica". Enquanto a primeira tem uma associação próxima e, em minha opinião, infeliz com pedagogias centradas no aluno e com a ênfase no "aprender da experiência", a segunda, embora faça parte de uma herança intelectual muito mais ampla, remontando a Kant e ao Iluminismo do século XVIII, tem sido relacionada, em estudos educacionais, à retórica oca do muito que passa por pedagogia crítica.

O restante deste texto trata de como pensamos sobre o currículo. Consta de duas partes. Primeiramente me refiro ao exemplo das reformas de 2008 do currículo nacional na Inglaterra, que descrevo como adotando uma abordagem "instrumentalista”. Mais tarde explicarei o que quero dizer com isso. Argumentarei que, em vez disso, precisamos conceber o currículo não como um instrumento para alcançar objetivos tais como "contribuir para a economia" ou "motivar aprendizes descontentes", mas como intrínseco ao motivo por que, afinal, temos escolas. A segunda parte do artigo desvia o foco do currículo para as escolas e sugere como disciplinas escolares podem ser consideradas o recurso mais importante para o trabalho dos professores e dos alunos na escola.

$\mathrm{Na}$ seção final, trato dos dois argumentos mais fortes apresentados contra um currículo centrado em disciplinas, ou, mais amplamente, centrado no conhecimento. O primeiro argumento é que qualquer forma de currículo centrado em disciplinas continuará a discriminar os menos favorecidos e, principalmente, os alunos da classe trabalhadora e de minorias étnicas. Essa questão é particularmente urgente no Reino Unido no momento. Um currículo tradicional, centrado em disciplinas, é fortemente endossado pelo novo e conservador ministro de Estado, Michael Gove. Um mês antes da eleição geral, ele foi citado dizendo que era adepto convicto de um currículo tradicionalista e acreditava que a maioria dos pais queriam que seus filhos: "se sentassem em fileiras, aprendessem sobre reis e rainhas, lessem obras importantes, fizessem cálculos mentais, começassem a aprender álgebra aos 11 anos e aprendessem línguas estrangeiras" (Gove, 2009). 
É importante distinguir entre a visão tradicional de Gove de um currículo centrado em disciplinas e a visão de currículo que eu defendo. Isso será feito de duas maneiras: em termos de seus diferentes conceitos de conhecimento, e em termos das diferentes suposições que fazem quanto aos relacionamentos dos aprendizes com o conhecimento.

O modelo tradicional trata o conhecimento como dado e como algo que os estudantes têm de acatar. Em contraste, embora o modelo que defendo também trate o conhecimento como exterior aos aprendizes, ele reconhece que essa exterioridade não é dada, mas tem uma base social e histórica. Também distingo o modelo que defendo do tradicional, pelos seus diferentes relacionamentos com os aprendizes e, portanto, suas diferentes implicações para a pedagogia e o que é feito por professores e alunos. À visão tradicional de Gove me referirei como um "currículo baseado em acatamento", e a minha como um "currículo baseado em engajamento".

O que os dois modelos têm em comum e como se situam em contraste com o modelo instrumentalista que sustenta as reformas de 2008 na Inglaterra é que ambos partem do conhecimento e não do aprendiz nem dos contextos enfrentados pelos aprendizes, como é sugerido por currículos projetados para se adequarem ao futuro emprego do aluno.

O segundo argumento contra um currículo centrado em disciplinas, sobre o qual comentarei mais brevemente ao final, é a afirmação de que ele está em desacordo com o que é frequentemente proclamado como uma tendência global para a desdiferenciação, em outras palavras, para o enfraquecimento das fronteiras entre ocupações e domínios de conhecimento.

\section{AS REFORMAS DE 2008 NA INGLATERRA: CURRÍCULOS INSTRUMENTALISTAS E SEUS PROBLEMAS}

Políticas curriculares desenvolvem-se, inevitavelmente, em contextos sociais, políticos e econômicos. Meu argumento é que na última década, sob pressões globais bem conhecidas, os formuladores de currículos no Reino Unido deram importância demasiada a esses contextos, em dois sentidos. Primeiramente, responderam à pressão do governo, contribuindo para a solução de problemas sociais tais como o desemprego. Em segundo lugar, também responderam ao que percebiam como necessidades e interesses dos aprendizes, especialmente daqueles com baixo rendimento na escola ou que a abandonavam cedo.

Em consequência, as propostas ignoraram, ou pelo menos secundarizaram, o papel educativo fundamental do currículo, que se deriva tanto do propósito das escolas como do que elas podem ou não podem fazer. Embora não devamos esquecer o contexto mais amplo, escolhas curriculares têm de ser tratadas pelo que são: maneiras alternativas de promover o desenvolvimento intelectual de jovens. Quanto mais nos focamos na possibilidade de um currículo reformado resolver problemas 
sociais ou econômicos, tanto menos provável que esses problemas sejam tratados em suas origens, que não se encontram na escola.

O ex-primeiro ministro Tony Blair uma vez declarou: "A educação é a melhor política econômica que temos”. Isso dizia muito, por extensão, sobre suas políticas econômicas. No entanto, também representa o tipo de instrumentalismo que tem infestado as políticas educacionais na Inglaterra nos últimos trinta anos; trata do que os políticos esperam que a educação possa fazer "como um meio" e não da sua razão de ser "como um fim". É como se questões sobre as finalidades da educação fossem demasiadamente filosóficas e abstratas para formuladores de políticas e políticos. Lamentavelmente, filósofos da educação tendem a exacerbar o problema ao invocar ideias como "bem-estar" (White, 2007). Naturalmente, o bem-estar humano é um objetivo importante para todas as sociedades; contudo, é tanto um objetivo para famílias e comunidades quanto para escolas, e diz pouco sobre o papel específico das escolas.

As principais prioridades das reformas de 2008 foram dar menos peso ao conteúdo das disciplinas e mais peso aos temas tópicos que atravessam um largo espectro de disciplinas e procurar maneiras de personalizar o currículo, relacionando-o mais diretamente ao conhecimento e às experiências cotidianas do aluno. Os formuladores de currículos começaram com dois problemas genuínos que certamente não ocorrem apenas na Inglaterra: um currículo "superlotado" e demasiados alunos descontentes. As reformas tentavam ligar os dois para explicar o fracasso das escolas em motivar uma proporção significativa de estudantes. O currículo reformado enfatizava sua flexibilidade e sua relevância para a experiência que os estudantes levam para a escola. Em outra palavras, o currículo era visto como um instrumento para motivar os estudantes a aprenderem.

\section{POR QUE ISSO É UM PROBLEMA?}

Meu argumento baseia-se em um curto texto de Tim Oates (2009). É que uma abordagem instrumentalista ao currículo tanto distorce o que qualquer currículo pode fazer, quanto confunde duas ideias educacionais crucialmente distintas. A primeira ideia diz respeito a currículo, que se refere ao conhecimento que um país considera importante que esteja ao alcance de todos os estudantes. A segunda ideia diz respeito à pedagogia, que, em contraste, se refere às atividades dos professores para motivar os alunos e ajudá-los a se engajarem no currículo e torná-lo significativo.

Currículo e pedagogia, sugiro, precisam ser vistos como conceitualmente distintos. Referem-se às responsabilidades distintas de formuladores de currículo e de professores, e cada um depende do outro. Enquanto os professores não podem, 
eles próprios, criar um currículo, mas precisam dele para guiá-los no que devem ensinar, os formuladores de currículos apenas podem estipular os conceitos importantes aos quais os alunos precisam ter acesso. Os formuladores de currículo contam com os professores para motivar os estudantes e transformar esses conceitos em uma realidade para os alunos.

Tentativas de incluir as experiências dos alunos em um currículo "mais motivador" obscurecem a distinção currículo/pedagogia e os papéis muito diferentes de formuladores de currículo e professores. Como a maioria dos professores sabe bem, eles têm de levar em conta as experiências e o conhecimento anterior que os alunos levam para a escola e o que os motiva inicialmente. Isso faz parte dos recursos que os professores têm para mobilizar estudantes, e constitui a base para que os estudantes se tornem aprendizes ativos. Isso, porém, é bastante diferente de incluir essas experiências no currículo.

Quero mencionar dois outros problemas que podem surgir de uma visão instrumentalista do currículo. Ambos se relacionam com o obscurecimento da distinção entre currículo e pedagogia e, por isso, ambos levam diretamente a uma discussão sobre o papel que as disciplinas têm no currículo. Primeiramente, uma visão instrumentalista do currículo pode levar a um efeito perturbador, vivamente demonstrado nas diretrizes da Qualifications and Curriculum Development Agency (QCDA) (Agência de Qualificações e Desenvolvimento de Currículo) na internet (vide http://www.qcda.gov.UK/curriculum/36.aspx). Refiro-me, especificamente, à proliferação de diretrizes específicas para professores. Embora os professores não sejam obrigados estatutariamente a adotar essas diretrizes, a natureza autoritária de suas origens no QCDA, juntamente com suas ligações com especificações de disciplinas em que se baseiam os exames, fazem-nas difíceis de ignorar. Parece que as diretrizes presumem que a solução para a falta de motivação dos estudantes seja dar mais orientação curricular para os professores, em vez de fortalecer e apoiar seu conhecimento pedagógico e da matéria e, consequentemente, seu profissionalismo.

Em um contexto político mais amplo, no qual se dá muita importância às notas dos alunos e aos resultados de testes e no qual as escolas podem ser hierarquizadas nacionalmente segundo o número de alunos que recebem certificados, não é exagero sugerir que o currículo em si está tornando-se cada vez mais uma forma de prestar contas em vez de ser um guia para professores. Dois exemplos contrastantes de especificações curriculares ilustram essa questão. Um veio da QCDA e estava sendo usado por uma escola do governo; tinha dez ou doze páginas. O outro, de um Conselho de Exames (Examination Board), estava sendo usado por uma escola particular paga e ocupava uma página e meia. Ambos tratavam da questão de qualidade. Entretanto, tinham ideias bem diferentes quanto ao profissionalismo 
do professor, quanto à distinção entre currículo e pedagogia, bem como quanto até que ponto se podia confiar nos professores.

O segundo problema que surge quando se trata o currículo como um "instrumento" é que se faz possível aos governos alegar que problemas econômicos ou sociais podem ser "solucionados" por mudanças no currículo. Não nego que o currículo deve estar sempre aberto ao debate democrático. No entanto, a não ser que exigências políticas dos governos tenham de enfrentar critérios educacionais explícitos dos formuladores de currículo sobre o que um currículo pode fazer, há o perigo de se negligenciar a finalidade mais fundamental da educação escolar, que é levar os alunos para além de sua experiência por formas às quais eles dificilmente teriam acesso em casa. Certamente é para isso que são as escolas.

Resumindo meu argumento até agora: primeiramente, o currículo precisa ser visto como tendo uma finalidade própria - o desenvolvimento intelectual dos estudantes. Não deve ser tratado como um meio para motivar estudantes ou para solucionar problemas sociais.

Em segundo lugar, o desenvolvimento intelectual é um processo baseado em conceitos, e não em conteúdos ou habilidades. Isso significa que o currículo deve ser baseado em conceitos. Entretanto, conceitos são sempre sobre alguma coisa. Eles implicam alguns conteúdos e não outros. O conteúdo, portanto, é importante, não como fatos a serem memorizados, como no currículo antigo, mas porque sem ele os estudantes não podem adquirir conceitos e, portanto, não desenvolverão sua compreensão e não progredirão em seu aprendizado.

Em terceiro lugar, deve-se distinguir currículo e pedagogia, uma vez que se relacionam de modo diferente com o conhecimento escolar e com o conhecimento cotidiano que os alunos levam para a escola. O currículo deve excluir o conhecimento cotidiano dos estudantes, ao passo que esse conhecimento é um recurso para o trabalho pedagógico dos professores. Os estudantes não vão à escola para aprender o que já sabem.

Em quarto lugar, são os professores com sua pedagogia, e não os formuladores de currículos, que se servem do cotidiano dos alunos para ajudá-los a se engajarem com os conceitos definidos no currículo e perceberem sua relevância.

Finalmente, o conhecimento incluído no currículo deve basear-se no conhecimento especializado desenvolvido por comunidades de pesquisadores. Esse é um processo que foi descrito como recontextualização do currículo (Barnett, 2006). No entanto, essas comunidades de pesquisa não se envolvem com as escolas. Por conseguinte, o currículo não pode estabelecer como se ganha acesso a esse conhecimento. Esse novo processo de "recontextualização" será específico para cada escola e para a comunidade em que se localiza, e baseia-se no conhecimento profissional dos professores. Por que, então, o currículo deve ser centrado em disciplinas? Esse é o tópico da segunda parte deste artigo. 


\section{DISCIPLINAS, O CURRÍCULO E OS OBJETIVOS DA ESCOLARIZAÇÃO}

Nesta seção, quero desviar o foco do currículo para a escola, e dos formuladores de currículo para os professores de disciplinas. Aqui, valho-me da obra do sociólogo e filósofo francês Bernard Charlot (2009). Ele inicia sua discussão estabelecendo o que é a escola e o tipo de lugar que a caracteriza. Ressaltarei cinco passos relacionados na elaboração de seu argumento.

As escolas são lugares onde o mundo é tratado como um "objeto de pensamento" e não como um "lugar de experiência”. Disciplinas como história, geografia e física são as ferramentas que os professores têm para ajudar os alunos a passarem da experiência ao que o psicólogo russo, Vygotsky, se referiu como "formas mais elevadas de pensamento". As disciplinas reúnem "objetos de pensamento" como conjuntos de "conceitos" sistematicamente relacionados.

Às vezes, esses conceitos têm referentes fora da escola, no ambiente da vida do aluno, numa cidade como Londres, por exemplo. Entretanto, os relacionamentos dos alunos com Londres como um "conceito" devem ser diferentes de seu relacionamento com a sua "experiência" de Londres como o lugar onde vivem.

É importante que os alunos não confundam a Londres de que fala o professor de geografia com a Londres onde vivem. Até certo ponto, é a mesma cidade, mas o relacionamento do aluno com ela, nos dois casos, não é o mesmo. A Londres onde vivem é um "lugar de experiência". Londres como exemplo de uma cidade é um "objeto de pensamento" ou um "conceito".

Se os alunos não conseguirem captar a diferença entre pensar em Londres como um exemplo do conceito dos geógrafos de uma cidade e sua experiência de viver em Londres, eles terão problemas para aprender geografia e, por analogia, qualquer disciplina escolar que busque levá-los para além de sua experiência. Por exemplo, a professora talvez pergunte à classe quais são as funções da cidade de Londres. Isso requer que os alunos pensem na cidade em relação ao governo e ao comércio, e não apenas que descrevam como eles, seus pais e seus amigos experimentam a vida na cidade.

Esse argumento pode ser expresso de outra forma, como segue. Os conceitos "teóricos" de disciplinas como geografia e os conceitos "cotidianos" que constituem a experiência que os alunos levam para a escola são diferentes e usá-los envolve processos de pensamento muito diferentes. Novamente, foi Vygotsky que em primeiro ressaltou essas diferenças. Vale a pena resumi-las.

Conceitos teóricos originam-se em comunidades de especialistas produtores de conhecimentos, como físicos e geógrafos. Esses conceitos têm finalidades específicas pelo fato de nos capacitarem a fazer generalizações confiáveis a partir de casos particulares e testá-las. Conceitos teóricos são sistematicamente relacionados uns aos outros (em matérias e disciplinas), e são adquiridos consciente e voluntariamente por meio da pedagogia nas escolas, faculdades e universidades. 
Em contraste, conceitos cotidianos são "captados" inconscientemente por todos em suas vidas diárias e são adquiridos pela experiência de formas ad hoc para propósitos específicos, relacionados com problemas particulares, em contextos particulares.

Eles formam o conhecimento de que necessitamos para viver em sociedade. As disciplinas, portanto, são conjuntos de conceitos teóricos relacionados, tais como a cidade e os subúrbios para geógrafos urbanos e professores de geografia. Também são as formas de organização social que reúnem especialistas em disciplinas e lhes dão suas identidades.

Às vezes, em geografia como em outras disciplinas, conceitos curriculares não têm um referente no ambiente de vida do aluno. Tais conceitos pertencem apenas a um mundo específico, constituído por pesquisadores especialistas envolvidos em desenvolver conhecimento novo. Bons exemplos são elétrons e átomos em ciências. Ao mesmo tempo, porque foram estudados e testados por especialistas, o acesso a eles é o modo mais confiável que temos para ampliar a compreensão do estudante.

Charlot (2009) chega à conclusão de que os professores possuem duas tarefas pedagógicas fundamentais. A primeira é ajudar os estudantes a administrarem o relacionamento entre os conceitos das diferentes disciplinas que constituem o currículo e seus referentes em suas vidas cotidianas. A segunda é apresentar aos alunos conceitos que têm significados que não derivam de sua experiência nem se relacionam diretamente com ela.

As disciplinas, então, têm duas características como uma base de plano curricular. Primeiramente, consistem de conjuntos de conceitos relativamente coerentes que se relacionam distinta e explicitamente entre si. Disciplinas diferentes têm regras para definir as fronteiras entre elas e outras disciplinas e para estabelecer o modo como seus conceitos se relacionam. Essas regras variarão segundo a precisão com que são definidas; Bernstein (2000) usa os conceitos "hierárquico" e "segmentado" para distinguir disciplinas como física e literatura.

Em segundo lugar, as disciplinas também são "comunidades de especialistas" com histórias e tradições distintas. Por meio dessas "comunidades", professores em diferentes escolas e faculdades estão ligados uns aos outros e àqueles que estão nas universidades produzindo novos conhecimentos. Cada vez mais, professores em países diferentes também se ligam por meio de periódicos, conferências e internet.

Duas características distinguem essa visão de disciplina, que é associada com aquilo a que me referi como um "currículo de engajamento", da visão tradicionalista de disciplina associada a um "currículo de acatamento". A primeira é que as disciplinas são entidades históricas dinâmicas que mudam com o tempo, em parte por desenvolvimento interno graças aos especialistas, em parte por pressões políticas externas e outras pressões. Em contraste com a visão tradicional de disciplinas, elas não são vistas como parte de algum cânone fixo definido pela tradição, com conteúdos e métodos imutáveis. Isso não significa que seja possível haver uma 
matéria ou uma disciplina sem algum tipo de "cânone" de textos, conceitos e métodos acordados. Isso significa que o cânone em si tem uma história e, embora não seja fixo e imutável, tem uma estabilidade, bem como uma abertura em que os estudantes podem apoiar-se ao estabelecerem suas identidades.

A segunda diferença é que, ao adquirirem conhecimentos das disciplinas, os estudantes não apenas acatam as regras e os conteúdos específicos como se fossem instruções. Ao adquirirem conhecimentos das disciplinas, eles estão ingressando naquelas "comunidades de especialistas", cada uma com suas diferentes histórias, tradições e modos de trabalhar. As disciplinas, portanto, têm três papéis num "currículo de engajamento". O primeiro é um papel curricular. As disciplinas garantem, por meio de seus elos com o processo de produção de novos conhecimentos, que os estudantes tenham acesso ao conhecimento mais confiável disponível em campos particulares. O segundo papel é pedagógico. As disciplinas oferecem pontes aos aprendizes para que passem de seus "conceitos cotidianos" aos "conceitos teóricos" a elas associados. O terceiro é um papel gerador de identidade para professores e aprendizes. As disciplinas são cruciais para o senso de identidade dos professores como membros de uma profissão.

O conhecimento da disciplina fornece aos professores a base de sua autoridade sobre os alunos. Para os alunos, passar de seu mundo cotidiano, no qual conceitos são desenvolvidos por experiência em relação a problemas que surgem em contextos específicos, para o mundo da escola, que trata o mundo como um objeto sobre o qual se pensa, pode ser uma experiência ameaçadora e mesmo estranha. $\mathrm{O}$ mundo cotidiano não é como a escola. Não se divide em matérias ou disciplinas. Esse papel gerador de identidade das disciplinas é particularmente importante para alunos de lares desfavorecidos e para seus professores. Muitos desses alunos chegarão à escola com pouca experiência de tratar o mundo como mais que um conjunto de experiências, em outras palavras, conceitualmente. As disciplinas, com suas fronteiras para separar aspectos do mundo que foram testados ao longo do tempo, não só oferecem a base para analisar e fazer perguntas sobre o mundo, como também oferecem aos estudantes uma base social para um novo conjunto de identidades como aprendizes. Com as novas identidades referentes às disciplinas, que os estudantes adquirem pelo currículo, acrescentadas àquelas com que vieram para a escola, eles têm mais probabilidades de serem capazes de resistir ao senso de alienação de suas vidas cotidianas fora da escola ou, ao menos, melhor lidar com ele. A escola pode promover tal capacidade.

Como ex-professor de química e de sociologia, tenho alguma ideia sobre os conceitos de química, como periodicidade e valência, e sobre os de sociologia, como solidariedade e classe social. Tais conceitos, bem como os relacionamentos entre eles e com o mundo da vida cotidiana, têm suas próprias histórias no âmbito das disciplinas. Eles são o que constitui as disciplinas e oferecem as maneiras mais 
poderosas que temos para generalizar além de nossa experiência do mundo. É por essa razão que defendo as disciplinas como a base do currículo.

\section{CONCLUSÕES E DESAFIOS}

Desenvolvi um argumento defendendo o papel central das disciplinas no currículo escolar e indiquei algumas das razões pelas quais esse papel tem sido solapado por recentes desenvolvimentos curriculares. Resta, porém, uma quantidade de questões a serem tratadas.

Em muitos países, um currículo não centrado em disciplinas, mas em temas, linhas de investigação ou tópicos derivados dos interesses dos alunos, está sendo experimentado e tem sido atraente para professores e alunos. Parece resolver as questões de relevância curricular e do "interesse do aluno", além de conceber a experiência das disciplinas como uma forma de "tirania cultural". Meu argumento é que inevitavelmente faltará coerência a tais currículos, que muito explicitamente obscurecem a distinção currículo/pedagogia, e que, também, eles não oferecerão a base necessária para o progresso dos alunos. Os critérios para a escolha de tópicos ou temas seriam, em grande parte, arbitrários ou derivados das experiências individuais de professores, e não do conhecimento especializado de professores e pesquisadores, construído ao longo do tempo.

Em tal currículo, os professores teriam de contar mais com sua posição de autoridade na escola e não com o seu conhecimento de especialista na disciplina. Além disso, os estudantes poderiam ter dificuldades em estabelecer suas identidades como aprendizes escolares e tenderiam ou a uma lealdade pessoal a professores específicos ou a rejeitar a autoridade derivada da posição do professor, vendo-a como burocrática e ilegítima. Seria possível que aí se iniciasse o descontentamento que frequentemente os leva a abandonar a escola. Apesar desses problemas, o apoio a um currículo integrado ou temático provavelmente não desaparecerá, especialmente entre professores "radicais". Tais currículos parecem oferecer um modo de superar o problema de superespecialização. Como é que, em um currículo baseado em disciplinas, os alunos adquirem os recursos para "fazer conexões" e ganhar um senso do mundo como um "todo"? Essa questão é importante, mas está além do escopo deste artigo. Então, vou restringir-me a algumas breves observações. O problema de "conexão" não é fácil de resolver e não há nenhuma evidência de que a especialização intelectual tenha probabilidade de se reverter. Para as escolas, sugiro, é um problema pedagógico e não curricular. Em termos curriculares, não há alternativa às disciplinas que se mostre adequada e que defina os conceitos que queremos que os estudantes adquiram. Não há princípios curriculares gerais "de conexão", como eu pensava (ou esperava) há alguns anos, que talvez dessem algum sentido à ideia de “especialização conectiva” (Young, 1998). Minha resposta provisória é que a capa- 
cidade de conectar ou "atravessar fronteiras" pode ser desenvolvida por professores, e surge da força da identidade do estudante relacionada à disciplina, assim como dos problemas que ele/ela julga que os conceitos contidos nas disciplinas sejam incapazes de resolver adequadamente.

Existe um paralelo que precisa ser mais explorado entre essa questão e a ideia expressa por Abbott (2001) e mais recentemente por Moore (2011) e Muller (2011) que, no campo de produção de conhecimento, "uma forma de interdisciplinaridade" é uma parte normal do crescimento do conhecimento. É uma interdisciplinaridade que surge da abertura e suas limitações dos campos do conhecimento e não de algum princípio externo imposto. No contexto da escola, é responsabilidade do professor da disciplina monitorar, criticar e, às vezes, apoiar aqueles estudantes que lutam para se mover além das regras da disciplina.

O jornal The Observer expressou bem o ponto que desejo destacar. Ao elogiar o notável Movimento Venezuelano para a introdução do jovem oriundo das partes mais pobres do país à música clássica, o jornal comentou: "Dominar um instrumento clássico requer disciplina, sensibilidade e agilidade mental. É triste que um brilhante instrumento para a aprendizagem seja rotineiramente colocado nas mãos de crianças privilegiadas e não seja oferecido às mais pobres" (3 de outubro de 2010).

Se você realmente dominar o violino ou o violoncelo, você tem acesso à música que está além de seu instrumento. É isso que penso em relação às disciplinas.

Quero, finalmente, considerar duas objeções diferentes à minha defesa de um currículo centrado no conhecimento. A primeira é que, apesar de distinguir entre modelos de currículos de "acatamento" e de "engajamento", meu modelo de engajamento de um currículo centrado em disciplinas difere muito pouco do currículo tradicionalista apoiado pelo novo secretário de Estado britânico. Em outras palavras, ele inevitavelmente perpetuaria um sistema elitista e desigual e continuaria a negar oportunidades de aprendizagem a muitos estudantes de lares desfavorecidos. É um argumento familiar e consistente com a crítica às disciplinas que fiz em meu primeiro livro, Knowledge and Control (Young, 1971).

Fui levado a repensar minhas ideias anteriores sobre o conhecimento, o currículo e o papel da escolarização. Isso não significa que eu agora desconsidero como as escolas em sociedades capitalistas reproduzem a classe social e outras desigualdades. No entanto, o fato de que alguns meninos de famílias da classe trabalhadora são bem-sucedidos na escola, apesar de suas desvantagens culturais, e de que em muitos países meninas se saem melhor do que meninos (Marrero, 2008), a despeito da discriminação de gênero na sociedade, sugere que o papel das escolas e do currículo centrado em disciplinas é mais complexo do que apenas manter desigualdades.

Em sociedades desiguais como a Inglaterra, qualquer currículo escolar manterá essas desigualdades. Contudo, a escolarização também representa (ou pode 
representar, dependendo do currículo) os objetivos universalistas de tratar todos os alunos igualmente e não apenas como membros de classes sociais diferentes, grupos étnicos diferentes ou como meninos ou meninas.

A escolarização comum, com o objetivo de maximizar o desenvolvimento intelectual de todos os estudantes, pode ser considerada uma instituição como a ciência, a democracia e os sindicatos. Nenhuma delas realizou plenamente os objetivos que lhes são associados, mas nenhuma é apenas produto do capitalismo ou do colonialismo e suas divisões. A escolarização comum surgiu, em parte, das necessidades de um capitalismo industrial em expansão e das desigualdades de classe social geradas por ele. Contudo, também foi um produto do Iluminismo do século XVIII e dos valores de universalismo e igualdade a ele associados. As escolas e o currículo, assim como instituições políticas tais como a democracia e os sindicatos, estão em constante tensão com seu contexto. Não são apenas produtos desse contexto.

Seria ingenuidade imaginar que qualquer currículo pudesse superar desigualdades geradas em outro lugar. Sociedades capitalistas, em graus diferentes, sempre produzirão desigualdades em educação, saúde, moradia ou qualquer serviço público. Ao mesmo tempo, um currículo centrado em disciplinas tem um grau de objetividade baseado no pressuposto de que é a maneira mais confiável que já desenvolvemos para transmitir e adquirir "conhecimento poderoso". Ninguém imaginaria que a criação de conhecimento novo poderia começar com a experiência ou a vida do dia a dia. Dizem que Isaac Newton afirmou: "Se enxerguei mais longe, foi apenas por me apoiar nos ombros de gigantes". Isso também se aplica à aquisição de conhecimento. As disciplinas ligam a aquisição de novo conhecimento à sua produção. Negar isso no currículo não é diferente de negar acesso aos antirretrovirais a africanos com AIDS / HIV com o argumento de que isso mostra desrespeito por seus conhecimentos locais.

Podemos ligar esse argumento à minha discussão anterior sobre as disciplinas. Em geral, as famílias de classe média dão aos filhos condições de tratar o mundo como "um objeto" ou de um modo que apresenta alguns paralelos com as disciplinas, não apenas como uma experiência, diferentemente das famílias da classe trabalhadora. Não surpreende que os primeiros estejam mais bem preparados para um currículo centrado em disciplinas. Podemos considerar que se trata de um subsídio da classe média. Ao mesmo tempo, as disciplinas, com sua sequência, seu ritmo e sua seleção de conteúdos e atividades são o que mais nos levam, em educação, a oferecer aos estudantes acesso a um conhecimento confiável. Em outras palavras, idealmente, as disciplinas escolares expressam valores universais que tratam todos os seres humanos como iguais e não como membros de diferentes classes sociais, grupos étnicos ou meninos e meninas. As escolas de elite são bem-sucedidas por duas razões. Primeiro, pela capacidade que seus preços elevados lhes conferem para serem tanto social como intelectualmente seletivas. E, em segundo, porque elas têm 
recursos para recrutar os melhores entre os professores especializados nas disciplinas. A falta de professores bem qualificados é um dos maiores motivos pelos quais, em termos relativos, as escolas do governo não são tão bem-sucedidas. $O$ enfraquecimento da base de disciplinas do currículo tornará mais difícil para os estudantes distinguirem entre "objetos de pensamento", ou conceitos que constituem um currículo, e suas experiências. Uma razão pela qual o novo secretário de Estado britânico se engana é que ele está endossando um objetivo universalista: professores de matérias tratam todos os aprendizes igualmente; em um contexto não universalista: nem todos os estudantes têm o mesmo acesso a professores especializados nas diferentes disciplinas.

Uma segunda objeção ao meu recontextualizado "currículo de engajamento", centrado em disciplinas, é que ele não leva em conta as transformações globais da sociedade que aconteceram e ainda estão acontecendo. Aqui, posso apenas apresentar brevemente minha resposta: seria necessário um outro artigo. $\mathrm{O}$ enfraquecimento das fronteiras entre as disciplinas escolares e o conhecimento cotidiano é frequentemente apresentado como consistente com transformações políticas e econômicas associadas à globalização. Podemos traçar paralelos com o recente entusiasmo por uma mudança do que é tratado como conhecimento Modo 1 para o Modo 2 como a base para uma nova abordagem à produção de conhecimento (cf. Gibbons et al., 1994). Argumenta-se, então, a favor de um currículo escolar interdisciplinar ou temático, por ser mais afinado com o mundo "como está se tornando" (Young; Muller, 2010). Meu argumento aqui é que, mesmo que essas tendências globais possam constituir uma previsão precisa de mudança social nas ocupações, não temos embasamento para presumir que elas se aplicam quer às condições para a aquisição de conhecimento confiável, quer à sua produção.

A produção de conhecimento novo por meio de pesquisa e sua aquisição pela educação formal são fenômenos relativamente recentes na história da humanidade. Há um conjunto de trabalhos na sociologia do conhecimento que remonta pelo menos ao sociólogo francês Emile Durkheim, há mais de um século, explicando as condições que tornaram isso possível. Durkheim afirma que a diferenciação entre conhecimento e experiência, e entre conhecimento teórico e conhecimento cotidiano são as condições mais fundamentais para a aquisição e a produção de novo conhecimento (Durkheim, 1983; Young, 2008).

Concluirei citando Max Weber, o sociólogo alemão cuja carreira transcorreu entre 1890 e 1920. No final de seu famoso livro, A ética protestante e o espírito do capitalismo, escreveu: "Na civilização ocidental, e somente na civilização ocidental, aparecem fenômenos culturais [e o currículo centrado em disciplinas poderia ser considerado um, embora ele não estivesse se referindo a isso] que [como gostaríamos de pensar] se encontram numa linha de desenvolvimento que tem significância e validade universais" (apud Kronman, 2007).

Para alguns, isso pode parecer uma forma de neocolonialismo primitivo, tentar extrair um conjunto de ideias de seu contexto político e histórico e afirmar 
sua universalidade. Acho que Weber estava levantando uma pergunta com implicações muito profundas para nós que trabalhamos em educação. A pergunta seria mais ou menos esta: quais são as implicações educacionais e políticas de haver alguns conhecimentos com significados generalizáveis, e um grau de objetividade, que não podem ser reduzidos aos seus contextos ou origens? As implicações são: concluir se há motivos para negar acesso a tais conhecimentos à próxima geração, independentemente de seus backgrounds sociais ou culturais.

\section{REFERÊNCIAS}

Аввотт, Andrew. Chaos of disciplines. Chicago: Chicago University Press, 2001.

BARNETT, Michael. Vocational knowledge and vocational pedagogy. In: YounG, Michael. \& Gamble, Jeanne. (Eds.). Knowledge, curriculum and qualifications for South African further education. Pretoria: HSRC Press, 2006.

Bernstein, Basil. Pedagogy, symbolic control, and identity: Theory, research, critique. Oxford: Rowman \& Littlefield, 2000.

Charlot, Bernard. School and the pupils' work. Sisifo. Educational Sciences Journal, 10, p. 87-94, 2009. Disponível em: <http://sisifo.fpce.ul.pt >.

Christie, Frances; MATon, Karl. Disciplinarity: Functional Linguistics and Sociological Perspectives. London, Continuum (no prelo).

Durkheim, Émile. Pragmatism and sociology. Trad. de J. C. Whitehouse. Cambridge: Cambridge University Press, 1983.

Gibbons, Michael; Limoges, Camile., Schwartzman, Simon.; Nowotny, Helga.; TRow, Martin.; Sсотт, Peter. The new production of knowledge: The dynamics of science and research in contemporary societies. London: Sage, 1994.

Gove, Michael. Failing schools need new leadership. 2009. Disponível em: <http:// michaelgovemp.typepad.com/files/gove-2009-conference-speech-2.pdf>.

Kronman, Anthony T. Education's end: Why our colleges and universities have given up on the meaning of life. New HavenHaven, CT and London: Yale University Press, 2007. Marrero, Adriana. Hermione en Hogwarts o sobre el éxito escolar de las niñas.

Moore, Rob. Education and society: Issues and explanations in the sociology of education. London: Polity Press, 2004.

Mora (it), v. 14, n. 1. Disponível em: <http://www.scielo.org.ar/pdf/moral/v14n1/ v14n1a02.pdf>. 2008.

. Making the break: Disciplies and Disciplinarity. In: CHRIsTIE, Frances; Maton, Karl. Disciplinarity: Functional Linguistics and Sociological Perspectives, 2011. London, Continuum (no prelo).

Muller, Joahn. Through other's eyes: the fate of disciplines. In: Christie, Frances; 
Maton, Karl. Disciplinarity: Functional Linguistics and Sociological Perspectives. London, Continuum (no prelo).

OAtes, Tim. Missing the point. Identifying a well-grounded common core. Cambridge: Cambridge Assessment, 2009.

WHITE, John. What schools are for and why? Impact, 14, 2007. Disponível em: <http:// www.philosophy-of education.org/impact/impact_details.asp?id=14>.

Yates, Lyn; Young, Michael. Globalisation, knowledge and the curriculum. European Journal of Education, 45(1), p. 4-10, 2010.

Young, Michael. Knowledge and control: New directions for the sociology of education. London: Collier-Macmillan, 1971.

. The Curriculum of the Future. London, Routledge, 1998.

. Bringing knowledge back. In: From social constructivism to social realism in the sociology of education. London: Routledge, 2008.

. Education, globalisation and the "voice of knowledge". Journal of Education and Work, 22(3), p. 193-204, 2009a.

.What are schools for? In: Daniels, H.; Lauder, J.; Porter, J. (Eds.) Knowledge, Values and Educational Policy, p. 10-18. London: Routledge, 2009b.

. Alternative educational futures for a knowledge society. European Educational Research Journal, 9(1), p. 1-12, 2010.

. Why educators must differentiate knowledge from experience. Pacific Asian Education, 22(1), 2011.

; MulLER, Joahn. Three educational scenarios for the future: Lessons from the sociology of knowledge. European Journal of Education, 45(1), p. 11-27, 2010.

\section{SOBRE O AUTOR}

Michael F. D. Young é doutor honoris causa pela Universidade de Joensuu (Finlândia). Professor titular da Universidade de Londres e da Universidade de Bath. Professor honorário nas Universidades Capital Normal (Beijing) e Pretória (África do Sul) e professor visitante da Universidade de Witwatersrand, Johannesburg.

E-mail: m.young@ioe.ac.uk

Recebido em fevereiro de 2011 Aprovado em abril de 2011 
pero advierte contra su reificación, ya que los procesos concretos no bacen tal distinción. Asi , la venta de mercaderias, la reserva de mercado y los proyectos de socialización configuran los curriculos escolares tan o más decisivamente que los encuentros de las concepciones propiamente pedagógicas. El artículo concluye que la "invasión" del campo de la educación por los mercados, dificulta la ampliación de su autonomía, lo que, por su vez, facilita la "invasión", generando un proceso de acción recíproca viciosa.

Palabras clave: política educacional; ideología; mercado curriculo; privatización.

\section{MICHAEL F. D. YOUNG}

\section{O futuro da educação em uma sociedade do conhecimento: o argumento radical em defesa de um currículo centrado em disciplinas}

O texto focaliza o papel, na educação, do conhecimento em si. Argumenta que, para se dar um sentido sério à importância da educação, é fundamental tornar a questão do conhecimento foco central das análises no campo da educação, o que requer o desenvolvimento de uma abordagem do currículo baseada mais no conhecimento e na disciplina e menos no aprendiz e em seus interesses. Defende, ainda, que essa é uma opção radical.

$\mathrm{O}$ artigo sustenta que, em termos curriculares, não há nenhuma alternativa às disciplinas que se mostre adequada e que defina os conceitos que os alunos devem adquirir. Assevera, ainda, que o papel das escolas e do currículo centrado em disciplinas é bem mais complexo do que simplesmente manter desigualdades. Afirma que as disciplinas permitem que se ofereça aos alunos um conhecimento confiável. Por fim, considera que, embora as tendências globais possam prever mudanças nas ocupações, não se pode presumir que elas se aplicam à produção ou à aquisição do conhecimento confiável.

Palavras-chave: educação; currículo; conhecimento; disciplina.

The future of education in a society of knowledge: the radical argument in defense of a curriculum based on course content

This article focuses on the role of knowledge in education. It argues that to take serious account of the importance of education, it is essential to make the issue of knowledge central to analyses in the field of education. This requires the development of a curricular approach based more on knowledge and on course contents and less on the student and his or her interests. It also affirms that this is a radical option.

The article maintains that in terms of curriculum, there is no alternative to the course contents that prove to be suitable and which define the concepts that the students must acquire. It also asserts that the role of schools and of curriculum focused on courses is 
much more complex than a simple question of maintaining inequalities. It affirms that courses allow offering students reliable knowledge. The paper concludes that although global trends may foresee changes in occupations, it cannot be presumed that they apply to production or acquisition of reliable knowledge.

Keywords: education; curriculum; knowledge; course content.

\section{El futuro de la educación en una sociedad del conocimiento: el argumento radical en defensa de un currículo centrado en diciplinas}

El texto focaliza el papel, en la educación, del conocimiento en sí. Argumenta que, para darse un sentido serio a la importancia de la educación, es fundamental tornar la cuestión del conocimiento en foco central del análisis en el campo de la educación, lo que requiere el desarrollo de un abordaje del currículo fundamentado más en el conocimiento y en la disciplina y menos en el aprendiz y en sus intereses. Defiende, todavia, que esa es una opción radical. El articulo sustenta que, en términos curriculares, no hay ninguna alternativa a las disciplinas que se muestren adecuadas y que definan los conocimientos que los alumnos deben adquirir. Asegura, todavía, que el papel de las escuelas y del currículo centrado en disciplinas es bien más complejo de lo que simplemente mantener desigualdades. Afirma que las disciplinas permiten que se ofrezca a los alumnos un conocimiento confiable. Por fin, considera que aunque las tendencias globales puedan prever mudanzas en las ocupaciones, no se puede presumir que ellas se apliquen a la producción o a la adquisición del conocimiento confiable.

Palabras clave: educación; currículo; conocimiento; disciplina.

\section{CÁSSIA GECIAUSKAS SOFIATO E LUCIA HELENA REILY}

\section{“Companheiros de infortúnio": a educação de "surdos-mudos” e o repetidor Flausino da Gama}

Este trabalho tem como objetivo apresentar a trajetória educacional de Flausino José da Costa Gama, aluno do Imperial Instituto dos Surdos-Mudos do Rio de Janeiro no século XIX. Flausino, além de ter sido um aluno e "repetidor" exemplar, segundo registros da época, destacou-se também pela criação da primeira obra de língua de sinais de que se tem notícia no Brasil: a Iconographia dos Signaes dos Surdos-Mudos, em 1875. Por meio de uma pesquisa bibliográfica e documental, apresentamos a proposta pedagógica do Imperial Instituto dos Surdos-Mudos e seus objetivos educacionais à época em que o diretor era o Dr. Tobias Leite e evidenciamos o percurso educacional de Flausino, primeiramente trazendo a sua biografia e todo o seu desenvolvimento a partir do ingresso na referida instituição. Além disso, destacamos o contexto no qual 